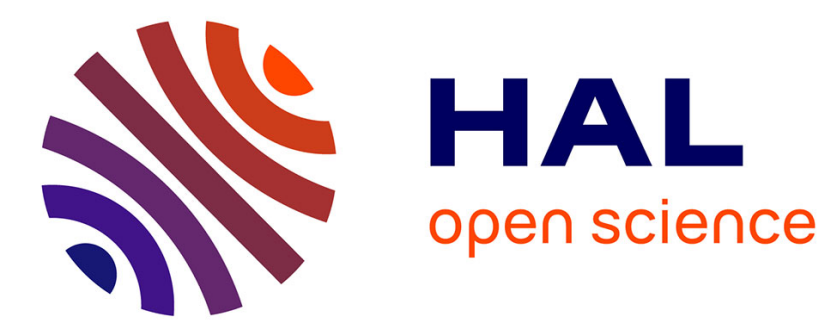

\title{
The mineralocorticoid receptor in chronic kidney disease
}

\author{
Jonatan Barrera-chimal, Frédéric Jaisser, Hans-joachim Anders
}

\section{To cite this version:}

Jonatan Barrera-chimal, Frédéric Jaisser, Hans-joachim Anders. The mineralocorticoid receptor in chronic kidney disease. British Journal of Pharmacology, 2021, 10.1111/bph.15734 . hal-03553183

\section{HAL Id: hal-03553183 \\ https://hal.science/hal-03553183}

Submitted on 25 Feb 2022

HAL is a multi-disciplinary open access archive for the deposit and dissemination of scientific research documents, whether they are published or not. The documents may come from teaching and research institutions in France or abroad, or from public or private research centers.
L'archive ouverte pluridisciplinaire HAL, est destinée au dépôt et à la diffusion de documents scientifiques de niveau recherche, publiés ou non, émanant des établissements d'enseignement et de recherche français ou étrangers, des laboratoires publics ou privés. 


\title{
The mineralocorticoid receptor in chronic kidney disease
}

\author{
Jonatan Barrera-Chimal ${ }^{1,2}$, Frederic Jaisser ${ }^{3,4^{*}}$, and Hans-Joachim Anders ${ }^{5 *}$
}

${ }^{1}$ Instituto de Investigaciones Biomédicas, Universidad Nacional Autónoma de México, Ciudad Universitaria, Mexico City, Mexico

${ }^{2}$ Laboratorio de Fisiología Cardiovascular y Trasplante Renal, Unidad de Investigación UNAM-INC, Instituto Nacional de Cardiología Ignacio Chávez, Mexico City, Mexico

${ }^{3}$ INSERM, UMRS 1138, Centre de Recherche des Cordeliers, Sorbonne Université, Université de Paris, Paris, France.

${ }^{4}$ Université de Lorraine, INSERM Centre d'Investigations Cliniques-Plurithématique 1433,

UMR 1116, CHRU de Nancy, French-Clinical Research Infrastructure Network (F-CRIN)

INI-CRCT, Nancy, France.

${ }^{5}$ Medizinische Klinik und Poliklinik IV, LMU Klinikum, Ziemssenstr. 1, D-80336, München

Word count: 5214

Running title: MR antagonism in kidney disease

*Shared senior authorship

\section{Corresponding authors}

Frédéric Jaisser, MD, PhD, FASN, FAHA

Address: Centre de Recherche des Cordeliers

15 rue de l'Ecole de Médecine, 75270 Paris cedex 06

Phone : + 33144276485

Fax: + 33144276421

E-mail: frederic.jaisser@inserm.fr

Prof. Dr. med. H.-J. Anders

Address: Medizinische Klinik und Poliklinik IV, LMU Klinikum

Ziemssenstr. 1, D-80336 München

Phone : +49-89-440032623

Fax:+49-89-440031542

E-mail: Hans-Joachim.Anders@med.uni-muenchen.de 


\begin{abstract}
Chronic kidney disease (CKD) is a major public health concern, affecting approximately $10 \%$ of the population worldwide. CKD of glomerular or tubular origin leads to the activation of stress mechanisms, including the renin angiotensin aldosterone system and mineralocorticoid receptor (MR) activation. Over the last two decades, blockade of the MR has arisen as a potential therapeutic approach against various forms of kidney disease. In this review, we summarize the experimental studies that have shown a protective effect of MR antagonists (MRAs) in non-diabetic and diabetic CKD animal models. Moreover, we review the main clinical trials that have shown the clinical application of MRAs to reduce albuminuria and, importantly, to slow CKD progression. Recent evidence from the FIDELIO trial showed that the MRA finerenone can reduce hard kidney outcomes when added to the standard of care in CKD associated with type 2 diabetes. Finally, we discuss the effects of MRAs relative to those of SGLT2 inhibitors, as well as the potential benefit of combination therapy to maximize organ protection.
\end{abstract}


Non-standard abbreviations:

CKD: Chronic kidney disease

GFR: Glomerular filtration rate

MR: Mineralocorticoid receptor

RAAS: Renin angiotensin aldosterone system

ACE: Angiotensin converting enzyme

MRAs: Mineralocorticoid receptor antagonists

ROS: Reactive oxygen species

NADPH: Nicotinamide adenine dinucleotide phosphate

TGF- $\beta$ : Transforming growth factor- $\beta$

MCP-1: Monocyte chemoattractant protein-1

NOS: Nitric oxide synthase

UUO: Unilateral ureteral obstruction

PKD: Polycystic kidney disease

AKI: Acute kidney injury

RCT: Randomized controlled trials

T2D: Type 2 diabetes

UACR: Urine albumin-to-creatinine ratio

ARB: Angiotensin II receptor blocker

SGLT: Sodium-glucose transporter 


\section{1- Functions of the kidney, definitions of kidney injury, and staging of kidney diseases}

The kidney is the key organ that maintains body homeostasis, i.e., the balance of water, salt, acids and bases, potassium, bone minerals, metabolic waste excretion, and oxygen sensing to regulate red blood cell production (Table 1). The filtration barrier of the kidney is fundamental for these processes and, hence, maintaining this barrier is another important function of the kidney. Although urine is no more than a side product of the aforementioned kidney functions, conceptually similar to air pollution not being a function but a side product of a technical plant, urinary abnormalities frequently indicate kidney dysfunction.

Chronic kidney disease (CKD) is defined by structural and functional abnormalities of the kidneys lasting more than three months, whereas "functional abnormalities" can also refer to impaired barrier function (albuminuria) or tubular function (electrolyte abnormalities) of the kidneys ("Chapter 1: Definition and classification of CKD," 2013). Instead, stages of CKD refer exclusively to clearance of the intrinsic metabolite creatinine (converted with formulas into an estimated glomerular filtration rate (GFR)) and to albuminuria as a marker of filtration barrier integrity.

\section{2- Overview of the pathophysiology of chronic kidney disease}

\subsection{Glomerular disorders}

Persistently impaired kidney function can have many causes, involving a large spectrum of diverse pathophysiological mechanisms. Regardless of when the injurious

process in the glomerular compartment starts, e.g., in genetic podocytopathies or glomerulonephritis, proteinuria is an early sign of filtration barrier injury and dysfunction (Kopp et al., 2020). Persistent proteinuria is frequently a sign of podocyte injury, which frequently progresses to irreversible glomerulosclerosis and nephron loss. Proteinuria increases the metabolic workload and cellular stress for the respective proximal tubule as it attempts to minimize the urinary loss of protein by maximizing protein breakdown in the brush border and transcellular reabsorption, which is energy consuming (Sharma \& Smyth, 2021). As the cellular stress in both compartments continues, irreversible loss of epithelial cells from glomeruli and tubules ultimately leads to the loss of entire nephrons. As the 
number of functioning nephrons declines, the filtration and reabsorption load for the remaining nephrons increases. A typical sign of single nephron hyperfiltration is an increase in proteinuria, which perpetuates the stress for the respective tubules (Anders, Huber, Isermann, \& Schiffer, 2018). Structural adaptations include cell hypertrophy and nephromegaly, which further drive glomerular scarring and interstitial fibrosis, both structural hallmarks of nephronopenia, requiring structural adaptations (Helal, FickBrosnahan, Reed-Gitomer, \& Schrier, 2012; Hostetter, Olson, Rennke, Venkatachalam, \& Brenner, 1981). The traditional concept that interstitial fibrosis itself contributes to nephron loss and CKD progression in glomerular disorders is poorly supported by the data (Kalluri \& Neilson, 2003). It is, therefore, of no surprise that drugs with specific antifibrotic effects fail to prevent CKD progression, (Voelker et al., 2017), whereas drugs that reduce the hemodynamic and metabolic nephron overload of nephrons strongly attenuate CKD progression (Heerspink et al., 2020).

\subsection{Tubular disorders}

CKD can arise from disorders that primarily affect the tubules, e.g., CKD following an episode of acute tubular necrosis, cystic kidney diseases, nephrocalcinosis, interstitial nephritis, IgG4 disease, and others (Romagnani et al., 2017). Such tubular injuries involve interstitial inflammation and fibrosis early on, even before nephron loss. Irreversible tubule injury leads to tubule atrophy and corresponding non-functional atubular glomeruli. (Chevalier \& Forbes, 2008). In addition, nephron loss results in an overload of the remaining nephrons, i.e., secondary filtration stress to the glomerular compartment and additional metabolic stress to the remaining tubules, driving further tubule cell loss and interstitial inflammation and fibrosis.

\subsection{Adaptation to nephron injury involves stress response programs}

Tissue injury triggers response programs that have been positively selected by evolution to increase survival, such as the coagulation cascade, inflammation, epithelial hypertrophy, stem-cell proliferation, and scarring (Anders, 2012). Each of these programs comes at the cost of trade-offs, such as immunopathology, cancer, and organ fibrosis, which all drive chronic organ dysfunction in those that survive the injury phase (Lei \& Anders, 
2017). Several signaling pathways play a key role in the stress response, including activation of the renin-angiotensin-aldosterone system (RAAS) and the neurohumoral axis, both leading to activation of the mineralocorticoid receptor (MR). They are both activated locally inside the kidney and systemically. Therefore, blocking these systems can minimize such trade-offs and improve outcomes in chronic organ failure. For example, beta-receptor blockers, angiotensin converting enzyme (ACE) inhibitors, and angiotensin receptor blockers (ARBs) improve outcomes of heart failure (van der Horst, Voors, \& van Veldhuisen, 2007). In addition, ACE inhibitors and ARBs also improve CKD (Ruggenenti et al., 1999; Vaduganathan et al., 2020). Similarly, MR agonists (MRAs) improve the outcomes of heart failure and CKD (Capelli et al., 2020), the latter discussed in more detail in this review.

An overview of the glomerular and tubulointerstitial causes of CKD is presented in Figure 1, along with the therapeutic approaches to slow CKD progression during the advancing stages of CKD by directly targeting the kidney or providing the control of cardiovascular risk.

\section{3- The MR and chronic kidney disease without diabetes}

Several studies have shown that MR activation can occur outside of aldosteronesensitive distal nephrons, including in vascular cells, inflammatory cells, podocytes, mesangial cells, and fibroblasts. The pathophysiological consequences of MR activation in these cells includes increased ROS generation, macrophage polarization towards an inflammatory state, T-cell activation, increased production of extracellular matrix proteins, leading to fibrotic remodeling, and hemodynamic alterations (for a review see (BarreraChimal, Girerd, \& Jaisser, 2019). Therefore, antagonizing the MR is an attractive therapeutic strategy to limit kidney injury by blocking these pathological mechanisms. In addition, nongenomic effects of aldosterone, including ROS generation by NADPH oxidase, hemodynamic effects and signaling by ERK1/2 and c-Jun, increased intracellular calcium, and protein kinase $\mathrm{C}$ activation have been reported (for a review see (Mihailidou, Tzakos, \& Ashton, 2019)). Thus, the benefit of MRAs may also be mediated by blocking the

nongenomic effects of aldosterone. For example, MRAs reduce hyperfiltration by the prevention of aldosterone-induced preferential vasoconstriction of efferent versus afferent 
renal arterioles (Arima et al., 2003), most likely explaining the rapid antiproteinuric effects of MRAs (G. L. Bakris et al., 2020; Bianchi, Bigazzi, \& Campese, 2005).

Over the last decade, extensive research has led to the development of fourthgeneration nonsteroidal MRAs (Kolkhof, Nowack, \& Eitner, 2015). The pharmacological differences between steroidal and non-steroidal MRAs are extensively reviewed elsewhere (Agarwal et al., 2021). Briefly, physicochemical and tissue penetration characteristics between these compounds may differ, leading to differential tissue distribution. For example, the nonsteroidal MRA finerenone shows balanced distribution between the heart and kidneys versus spironolactone or eplerenone, which preferentially concentrate in the kidneys (Kolkhof et al., 2014). Another difference is that finerenone has a shorter half-life than steroidal MRAs and does not have active metabolites, thus potentially reducing its long-term effects on sodium/potassium balance (Agarwal et al., 2021). Furthermore, nonsteroidal MRAs differ from steroidal MRAs in co-factor recruitment after binding to the MR, which may result in differential modulation of gene expression, leading to a stronger inhibition of inflammation and fibrosis at equi-natriuretic doses (Grune et al., 2018).

\subsection{MR antagonism alleviates kidney injury in various pre-clinical models of kidney disease} without diabetes

Kidney fibrosis is the common result of CKD of various origins. Pioneering studies demonstrated that spironolactone treatment of rats with subtotal nephrectomy transiently reduces proteinuria, lowers blood pressure, and reduces cardiac hypertrophy (Greene, Kren, \& Hostetter, 1996). It was later found that spironolactone treatment can also induce the regression of glomerulosclerosis in this subtotal nephrectomy CKD model (Aldigier, Kanjanbuch, Ma, Brown, \& Fogo, 2005). Recently, the non-steroidal aldosterone antagonist Ly was also shown to protect against albuminuria and kidney hypertrophy in the remnant kidney model with better efficacy than eplerenone (Fujihara et al., 2017).

MR inhibition has also shown protective effects in animal models of glomerulonephritis. In mice with proliferative glomerulonephritis induced by anti-Thy1.1 antibody, spironolactone showed antiproteinuric effects and reduced TGF- $\beta$ levels and glomerular injury and proliferation (Asai et al., 2004) (Gullulu, Akdag, Kahvecioglu, Filiz, \& Savci, 2006). In this model, eplerenone administration also has anti-inflammatory effects, 
as shown by decreased glomerular macrophage infiltration, MCP-1 expression, and mesangial phenotypic activation (Qin et al., 2013). Eplerenone also reduced albuminuria, glomerular sclerosis, and crescents in glomerulonephritis induced by anti-glomerular basement membrane antibody administration, accompanied by reduced infiltration of $\mathrm{CD}^{+}$ and $\mathrm{CD}^{+} \mathrm{T}$ cells and macrophages (Zitt et al., 2011)(Huang et al., 2014). The non-steroidal MRA BR-4628 also helped to maintain renal function, prevented glomerular tuft damage, and reduced glomerular crescents by 50\%, accompanied by reduced macrophage and T-cell infiltration (Ma, Han, Nikolic-Paterson, Kolkhof, \& Tesch, 2015).

MR antagonism has shown beneficial effects in several models of hypertensioninduced kidney injury that are independent from the effect on lowering blood pressure. Spironolactone prevented the appearance of nephrosclerotic injury and proteinuria in strokeprone spontaneously hypertensive rats (SHRs), even in the absence of blood pressure control (Rocha, Chander, Zuckerman, \& Stier, 1999). The new non-steroidal MR antagonist KBP5074 demonstrated better efficacy than eplerenone in reducing blood pressure, albuminuria, and kidney hypertrophy and injury in Dahl salt-sensitive rats and stroke-prone SHR (Cp, 2017). In SHR, in which chronic NOS inhibition exacerbates kidney lesions, eplerenone administration reduced proteinuria and structural lesions, despite there being no modifications in systemic or renal hemodynamics (Zhou, Ono, Ono, \& Frohlich, 2004). Similarly, glomerular sclerosis and proteinuria were prevented in a radiation injury hypertensive model (Brown et al., 2000). Eplerenone prevented podocyte injury and effacement, with a consequent delay in proteinuria and glomerulosclerosis, in the Dahl salt hypertensive rat model (Nagase et al., 2006). Thus, MR inhibition could help to maintain the glomerular filtration barrier through preventing podocyte damage. In Dahl rats, the nonsteroidal MRA esaxerenone reduced blood pressure, albuminuria, and structural injury (Li et al., 2019). In transgenic hypertensive rats (Cypla1Ren2 rats), spironolactone treatment started after the establishment of hypertension reduced proteinuria and halted glomerulosclerosis and the progression of fibrosis, independently of blood pressure normalization (Leader, Kelly, Sammut, Wilkins, \& Walker, 2020).

In mineralocorticoid-induced hypertension, eplerenone reduced hypertension and blunted albuminuria, kidney injury, and pro-inflammatory gene expression in SpragueDawley rats with aldosterone-salt plus unilateral nephrectomy (Blasi et al., 2003). The non- 
steroidal MRAs SM-368229, CS-3150 (esaxerenone), and AZD9977, have also shown promising effects on renal pathology in this context (Nariai et al., 2012) (Bamberg et al., 2018) (Arai, Morikawa, Ubukata, Tsuruoka, \& Homma, 2016). Similarly, the non-steroidal MRA KBP-5074 showed a better therapeutic index than eplerenone in a rat model of kidney injury induced by aldosterone, salt, and unilateral nephrectomy (Jaisser et al., 2021). Of note, AZ9977 showed a reduced effect on renal sodium excretion relative to that of eplerenone, while retaining its renal protection benefit (Bamberg et al., 2018).

A widely used model of kidney fibrosis consists of unilateral ureteral obstruction (UUO). Spironolactone reduced kidney fibrosis in mice subjected to UUO for two weeks (Trachtman, Weiser, Valderrama, Morgado, \& Palmer, 2004). In rats with UUO, eplerenone inhibited renal fibrosis and inflammation and reduced monocyte and macrophage infiltration, interstitial cell proliferation, and oxidative stress (Chen et al., 2013). Moreover, it also attenuated the fibrosis that develops in the contralateral kidney of UUO rats via inhibition of the macrophage to myofibroblast transition. (Xiong et al., 2021)

In a rat model of polycystic kidney disease (PKD), spironolactone treatment attenuated hypertension in female rats only. Spironolactone reduced albuminuria and plasma creatinine, but fibrosis and cyst size were not modified. Thus, MR antagonism was only partially protective against kidney injury in the rat PKD model (Jeewandara et al., 2015).

In kidney injury due to ischemia, spironolactone administration, before or even up to three hours after bilateral renal IR injury in the rat, limited acute kidney dysfunction and tubular injury by preventing the sustained fall in renal blood flow, reducing oxidative injury, increasing endothelial nitric oxide synthase activation, and inducing metabolic reprogramming (Mejia-Vilet et al., 2007) (Sanchez-Pozos et al., 2012) (Lindhardt et al., 2020). MR antagonism with the non-steroidal MRAs BR-4628 and finerenone showed similar protective effects in rat and mouse models of ischemic acute kidney injury (AKI) (Barrera-Chimal et al., 2016) (Lattenist et al., 2017). MR antagonism in ischemic AKI was further shown to be protective in the white large pig AKI pre-clinical model, in which MR antagonism with potassium canrenoate reduced urinary tubular injury markers and oxidative stress levels and, importantly, preserved kidney function and structure (Barrera-Chimal et al., 2017) (Melis et al., 2019). Moreover, spironolactone and finerenone have also been shown to be effective in preventing the transition to $\mathrm{CKD}$ following an ischemic AKI episode 
in rats and mice (Barrera-Chimal et al., 2013) (Barrera-Chimal et al., 2015) (Barrera-Chimal et al., 2018; Lattenist et al., 2017). Importantly, potassium canrenoate administration in the white large pig AKI model was also able to prevent AKI-induced CKD progression, with reduced kidney fibrosis and improved kidney function 90 days after the AKI episode (Barrera-Chimal et al., 2018). Thus, pre-clinical evidence supports MR antagonism as a reasonable strategy to prevent the acute and chronic alterations induced by ischemic AKI, which should be further explored in dedicated clinical trials.

In the transplantation setting, a chronic allograft dysfunction model in dark agouti to Wistar Furth rat kidney transplantation, spironolactone treatment from two days before and up to 12 weeks after transplantation significantly reduced vasculopathy and glomerular macrophage influx and showed a trend towards reduced proteinuria and glomerulosclerosis (Waanders et al., 2009). However, neither MR antagonism nor the inhibition of aldosterone synthase showed any protection against glomerulosclerosis or interstitial fibrosis in male Fisher-344 to male Lewis rat allograft injury (Lahmer et al., 2012). The use of calcineurin inhibitors as immunosuppressive drugs in organ transplantation is frequently restricted due to their acute or chronic nephrotoxic consequences. Spironolactone treatment of rats with acute cyclosporine A (CsA) nephrotoxicity was shown to maintain kidney function (McAuley, Whiting, Thomson, \& Simpson, 1987) and prevent the reduction in renal blood flow (J. M. Perez-Rojas et al., 2005). Eplerenone displayed a similar protective effect (Nielsen, Jensen, Marcussen, Skott, \& Bie, 2008). MR deletion in smooth muscle cells prevents the acute kidney dysfunction and injury induced by CsA (Amador et al., 2016). Spironolactone also prevented the fall in renal blood flow and GFR and prevented/or treated the tubulointerstitial fibrosis/expansion and arteriolopathy observed in a rat model of chronic calcineurin nephrotoxicity (J. M. Perez-Rojas et al., 2005) (Feria et al., 2003) (J. Perez-Rojas et al., 2007) (Nielsen, Jensen, Hansen, Marcussen, \& Bie, 2013).

As summarized in Figure 2, MRAs have shown beneficial effects in several preclinical models of kidney disease associated with hypertension, glomerulonephritis, and calcineurin inhibitor use and in fibrotic kidney disease and kidney transplantation settings. Non-steroidal MR antagonists show similar or even enhanced beneficial effects in preclinical models of kidney disease, thus supporting their clinical use for this indication. 
3.2 Clinical trials on mineralocorticoid receptor antagonism in kidney diseases without diabetes

Evidence for the effectiveness of MR antagonism in hard kidney disease outcomes is limited due to concerns about hyperkalemia in patients with reduced renal function. Clinical trials have thus far been limited due to the restricted use of MRAs in patients with advanced CKD.

Several randomized controlled trials (RCTs) have focused on the antiproteinuric effect of MRAs in CKD patients. Meta-analyses of these studies (Bolignano, Palmer, Navaneethan, \& Strippoli, 2014) (Currie et al., 2016) (Alexandrou et al., 2019) (Chung et al., 2020) showed that MRAs have a potent effect in reducing proteinuria, the urine albumin-tocreatinine ratio (UACR), and albumin excretion, alone or when they are combined with ACE inhibitors and ARBs. An antiproteinuric effect of MRAs has been reported in glomerulonephritis (Yu et al., 2018).

In non-diabetic $\mathrm{CKD}$, a recent single-blinded placebo-controlled trial that randomized 48 patients with stage $2-3 \mathrm{CKD}$ and plasma aldosterone $>15 \mathrm{ng} / \mathrm{dL}$ to eplerenone $(25 \mathrm{mg} / \mathrm{d})$ or placebo found that the estimated GFR (eGFR) dropped in the first six months after the initiation of eplerenone. However, at months 24 and 36, the eGFR was maintained and significantly higher than in the placebo arm (Minakuchi et al., 2020). In a retrospective analysis of pre-dialysis patients with stage 3-4 CKD, it was found that spironolactone users $(n=693)$ had a $34 \%$ lower risk of end-stage renal disease progression than non-users $(n=$ 1,386), but hyperkalemia-associated hospitalization rates were also higher (Yang, Kor, \& Hsieh, 2018). The phase $2 \mathrm{~b}$ BLOCK-CKD trial evaluated the efficacy and safety of the nonsteroidal MRA KBP-5074 (0.25 and $0.5 \mathrm{mg} /$ day) versus a placebo in 162 patients with stage 3b/4 CKD and resistant hypertension (G. Bakris, Yang, \& Pitt, 2020) (G. Bakris et al., 2021). After 84 days of follow-up, KBP-5074 significantly reduced systolic blood pressure by 7 $\mathrm{mmHg}$ in the $0.25 \mathrm{mg} /$ day and $10.2 \mathrm{mmHg}$ in the $0.5 \mathrm{mg}$ /day groups. The incidence of hyperkalemia was similar among the placebo and KBP-5074 groups, with no hyperkalemia events above $6.0 \mathrm{mmol} / \mathrm{L}$ observed and no hyperkalemia-related hospitalizations recorded (G. Bakris et al., 2021).

MR antagonism was tested in a pilot trial on 20 living-donor kidney transplantation (KT) patients, in which spironolactone $(25 \mathrm{mg})$ was administered from one day before up to 
three days after KT and resulted in a reduction in oxidative stress markers in the urine (OjedaCervantes et al., 2013). This effect was later confirmed in another study, in which higher spironolactone doses (50 and $100 \mathrm{mg}, \mathrm{n}=25$ ) reduced urinary 8-hydroxylated-guanosine levels, as a marker of oxidative stress, relative to a placebo in living-donor KT patients $(\mathrm{n}=$ 27) (Morales-Buenrostro et al., 2019). As these studies were performed on a small number of patients, more highly powered studies to evaluate the effect in postmortal donor KT, with a longer follow-up, are expected and will yield more information about the efficacy of MR antagonism in preventing delayed graft function and chronic effects. Indeed, the multicenter RCT EPURE, to evaluate the impact of short-term administration of eplerenone (immediately before and four days after KT) on three-month renal graft function in patients receiving a graft from an expanded-criteria donor, is currently ongoing and expected to randomize 132 patients (NCT02490904) (Girerd et al., 2018).

Concerning calcineurin toxicity in transplant patients, one RCT showed promising results, indicating that eplerenone may be helpful in reducing biopsy-proven chronic graft nephropathy in 23 pediatric patients (Medeiros et al., 2017). The SPIREN trial (NCT01602861) is currently evaluating the efficacy of spironolactone administration for three years among 170 prevalent kidney transplant patients. The primary endpoint is GFR, measured by chrome-EDTA clearance. Secondary outcomes are proteinuria, the amount of interstitial fibrosis in graft biopsies, and cardiovascular events (Mortensen et al., 2018). Of note, it was reported that spironolactone treatment for one year was not associated with changes in markers of endothelial dysfunction in a subgroup analysis of 80 patients from this trial (Mortensen et al., 2019).

Further studies are warranted in this area. It would be of interest to evaluate nonsteroidal MRAs in chronic allograft dysfunction, in which chronic MRA use is currently prohibited. Moreover, the impact of MRAs on the CV comorbidities associated with KT should be assessed based on the CV benefit reported in other settings.

Spironolactone administration in 115 cardiac surgery patients, $100 \mathrm{mg}$ the day before surgery and $25 \mathrm{mg} / \mathrm{d}$ during the three days after the procedure, did not demonstrate a benefit in post-operative AKI relative to placebo $(n=118)$ (Barba-Navarro et al., 2017). Indeed, a trend towards an increased risk in the spironolactone arm was observed (Barba-Navarro et al., 2017). Nonetheless, the trial was underpowered due to not achieving the planned sample 
size and randomization led to a higher proportion of diabetic patients in the spironolactone group (31 vs $18 \%, \mathrm{p}=0.02$ ). In a RCT in which the primary outcome was to test whether RAAS inhibition reduced the prevalence of atrial fibrillation after cardiac surgery, spironolactone was protective against AKI but no benefit was observed for atrial fibrillation (Pretorius et al., 2012). Ongoing trials will evaluate whether spironolactone can reduce the incidence and severity of AKI in critically ill patients on invasive mechanical ventilation when administered during the first five days of critical care after admission to the unit (NCT03206658) and the effect of short-term spironolactone administration on AKI prevention in postoperative patients following major surgery (NCT02531412). An additional study will evaluate spironolactone (200 mg/single dose) or placebo in contrast-induced nephropathy (NCT03329443) (Mujtaba et al., 2018).

In conclusion, the use of MRAs in pre-clinical models shows promise in targeting the development of fibrosis in the kidney due to various etiologies. Although the evidence in humans is scarce, post-hoc analyses of the effect of MRAs in cardiovascular-focused trials in which patients with reduced renal function were included, together with proof-of-concept trials, demonstrate that MR antagonism has beneficial effects on kidney health, despite the risk of hyperkalemia (Figure 2).

\section{MR and kidney disease with diabetes / metabolic disease}

\subsection{The role of diabetes in $C K D$}

Hyperglycemia induces immediate single nephron hyperfiltration via the deactivation of tubulo-glomerular feedback following a fascinating series of events, explained in detail elsewhere. Almost all young patients with type 1 diabetes and good nephron function easily handle diabetes-related hyperfiltration of the kidney and do not develop kidney damage for many decades, if at all. Indeed, this form of diabetic nephropathy has become rare for those with access to insulin (pump) therapy.

The onset of hyperglycemia in older people usually adds to precedent nephronopenia due to kidney ageing, previous injury, or concomitant nephropathies. In addition, type 2 diabetes (T2D) usually involves obesity, which is an independent cause of kidney overload. As such, it is no surprise that adults with T2D develop macroproteinuria at higher rates and 
much faster than young individuals without such comorbidities. Therefore, the concept of "diabetic kidney disease (DKD)" in adults is outdated and is now referred to as "CKD with diabetes". Indeed, in adults, the hemodynamic and metabolic stress imposed by diabetes on adult kidneys acts mostly as a cofactor to accelerate the progression of CKD, which at this age is generally of multifactorial nature.

\subsection{MR antagonism alleviates kidney injury in various pre-clinical models of kidney disease} associated with diabetes or metabolic disease

Several studies performed in mouse and rat models of type 1 or type 2 diabetes have shown that steroidal MRAs are effective in preventing kidney alterations, including excessive extracellular matrix deposition in the glomeruli and interstitium, oxidative injury, inflammatory cell infiltration, and proteinuria (Fujisawa et al., 2004; Guo et al., 2006; K. H. Han et al., 2006; S. Y. Han et al., 2006; Yuan, Jia, \& Bao, 2007). MRA use in DKD also prevents podocyte injury by reducing oxidative stress and activating autophagy (Dong et al., 2019; Toyonaga et al., 2011). As diabetes and hypertension often co-exist, the effect of spironolactone and eplerenone in mouse models of hypertensive and diabetic injury has also been explored, showing that both MRAs reduce albuminuria and fibrosis (Lian et al., 2012; Pessoa, Peixoto, Papadimitriou, Lopes de Faria, \& Lopes de Faria, 2012).

More recently, the efficacy of non-steroidal MRAs in diabetic models of kidney disease has been explored. Esaxerenone demonstrated protection against glomerular lesions, fibrosis, inflammation, and albuminuria in hypertensive mice with T2D (Bhuiyan et al., 2019). Of note, these beneficial effects were more pronounced for esaxerenone than for spironolactone, whereas the blood pressure was reduced to a similar extent (Bhuiyan et al., 2019). The nonsteroidal MRA AZD9977 was shown to reduce glomerular extracellular matrix deposition in type 2 diabetic $\mathrm{db} / \mathrm{db}$ mice (Bamberg et al., 2018).

Obesity and metabolic co-morbidities often lead to kidney injury. In a severe model that combines obesity, hypertension, and high salt (SHR/cps rat), massive proteinuria, severe renal lesions, and podocyte injury are observed. Eplerenone dramatically improved the proteinuria and renal injury of these animals (Nagase, Matsui, Shibata, Gotoda, \& Fujita, 2007). Mice with obesity induced by a high-fat diet develop kidney injury, characterized by glomerular hypercellularity, mesangium expansion, albuminuria, and increased rho kinase 
activity; all these alterations were attenuated by eplerenone (Tokuyama et al., 2012). High glucose increases Racl and MR transcriptional activity in cultured mesangial cells (Yoshida et al., 2014). In accordance with these observations, the inhibition of Rac1 reduced MR activity in the kidney and mitigated renal pathology in a mouse model of obesity-related T2D (KKA(y) mouse), even if plasma aldosterone levels were unchanged. (Yoshida et al., 2014) The non-steroidal MR antagonist finerenone improved metabolic syndrome-related nephropathy in rats with metabolic syndrome (Zucker fa/fa rats) by reducing proteinuria and neutrophil gelatinase-associated lipocalin (NGAL) levels(Lachaux et al., 2018).

\subsection{Clinical trials on mineralocorticoid receptor antagonism in kidney diseases with diabetes}

One meta-analysis of 16 studies including 789 DKD patients showed that spironolactone plus an ACE inhibitor or ARB significantly diminishes 24-h urinary albumin/protein excretion or the urinary albumin/creatinine ratio (Hou, Xiong, Cao, Wen, \& $\mathrm{Li}, 2015)$. As blood pressure was also reduced, it is possible that the antiproteinuric effect may be, at least partially, mediated by the reduction of blood pressure.

High dose eplerenone administered to $70 \mathrm{~T} 2 \mathrm{D}$ patients with a high risk of cardiovascular disease had a remarkable effect on UACR reduction versus a placebo $(\mathrm{n}=$ 70), while maintaining an acceptable safety level (Brandt-Jacobsen et al., 2020). The nonsteroidal MRA finerenone was first tested in DKD patients to evaluate its safety and efficacy for renal outcomes in the ARTS-DN study, in which a dose-dependent reduction of proteinuria was observed with finerenone in DKD patients receiving ACE inhibitors or ARBs (G. L. Bakris et al., 2015). These data led to the FIDELIO RCT, in which 5,734 patients with $\mathrm{CKD}$ and T2D were randomized to receive finerenone or placebo to evaluate the effects of finerenone on renal outcomes. After a 2.6-year median follow-up, finerenone was shown to reduce the primary renal outcome (a composite of time-to event, kidney failure, sustained decrease of at least $40 \%$ of baseline eGFR, or death from renal causes) by $18 \%$ (G. L. Bakris et al., 2020). A secondary outcome of a sustained decrease of $>57 \%$ in eGFR from baseline was reduced by $32 \%$ in the finerenone arm. The adverse events were similar for the placebo and finerenone groups, whereas hyperkalemia was more common in the finerenone $(2.3 \%)$ than placebo (0.9\%) group (G. L. Bakris et al., 2020). Other non-steroidal MR antagonists have also shown promising results in DKD. The non-steroidal MRA apararenone showed a 
significant reduction in UACR when administered for 24 weeks to stage 2 DKD patients (Wada et al., 2020). Similar anti-albuminuric effects were observed with esaxerenone treatment combined with RAS inhibitors for 12 weeks in patients with T2D and microalbuminuria (Ito, Shikata, Nangaku, Okuda, \& Sawanobori, 2019). Therefore, MR antagonism is a useful strategy to reduce hard renal outcomes in DKD patients.

In conclusion, Phase-2 clinical trials in DKD have been concluded for non-steroidal MR antagonists, such as esaxerenone and apararenone, while the largest phase- 3 clinical trial in DKD patients has been concluded for finerenone, with very exciting data on the prevention of hard renal outcomes.

\section{5- Sodium-glucose transporter inhibitors versus MR antagnoism}

The journey of basic and clinical MR research has been exciting because the dual effects of MRAs on the kidney itself and on the related cardiovascular comorbidity address many of the unmet medical needs of CKD patients, with or without diabetes (Agarwal et al., 2021; Barrera-Chimal et al., 2019). However, the evolving pathophysiological concept of hemodynamic and metabolic overload of a declining number of nephrons leaves space for numerous other molecular targets with potential renoprotective effects (Romagnani et al., 2017). Among them, inhibitors of the sodium-glucose transporter (SGLT)-2 are particularly potent. SGLT2 is expressed in the S2 and S3 segment of the proximal tubule, where it recovers sodium and glucose from the glomerular filtrate and therefore minimizes glucose loss into the urine (Vallon, 2015). The development of SGLT2 inhibitors as anti-diabetic drugs was based on the rationale of enhancing urinary glucose excretion and, indeed, SGLT2 inhibitors can reduce Hbalc by up to $1 \%$ and the negative calorie balance is associated with a reduction in lean body weight (Scheen, 2020). However, SGLT2 inhibition revealed an unexpected potency to reduce cardiovascular events by approximately 30 to $40 \%$ and several markers of CKD progression by 40 to $60 \%$ in large clinical trials that included patients with T2D, heart failure, and/or CKD (Perkovic et al., 2019; Wanner et al., 2016; Zannad et al., 2020; Zinman et al., 2015). Of note, background treatment with RAS inhibitors was $90 \%$ or more in all these trials (Perkovic et al., 2019; Wanner et al., 2016; Zannad et al., 2020; Zinman et al., 2015). A debate about the underlying mechanisms-of-action is still ongoing and includes diverse concepts, which are discussed elsewhere in detail (Thomas \& Cherney, 
2018; Vallon, 2015). Briefly, SGLT2 inhibition reduces the increased workload of the remaining nephrons of CKD kidneys in two ways. First, SGLT2 inhibition directly attenuates the workload of the proximal tubules by blocking sodium and glucose reuptake, which increases in the remaining nephrons as other nephrons undergo atrophy for reasons of aging or injury. (Vallon, 2015) Second, SGLT2 inhibition indirectly reduces the abnormal and cumbersome hyperfiltration of the remaining nephrons, i.e., mechanical shear stress at the delicate glomerular filtration barrier, and therefore reduces barrier injury, proteinuria, and glomerulosclerosis (Anders, Davis, \& Thurau, 2016; Thomas \& Cherney, 2018). Less glomerular filtration also implies less workload to the respective proximal tubules. Conceptually similar to beta-blockers, which reduce the workload of failing hearts, SGLT2 inhibitors reduce the workload of failing kidneys, which translates into longer organ survival.

The average effect size of a RAS/SGLT2 inhibitor combination exceeds the effect size of a RAS/finereone combination for primary kidney endpoints in patients with T2D and CKD, as reported by the FIDELIO trial (G. L. Bakris et al., 2020; Perkovic et al., 2019; Wanner et al., 2016). At this point, it is uncertain whether this difference will repeat in other patient cohorts, e.g., in patients with non-diabetic kidney disease or heart failure. Given the different mechanisms-of-actions of SGLT2 inhibition and MR antagnosim, one may speculate that a triple combination may be even more potent that either of the dual combinations. In support of an additive effect of SGLT2 inhibitors and MRAs, it was recently shown that a low-dose combination of finerenone and empagliflozin showed an additive effect in the reduction of albuminuria and cardiorenal structural lesions in hypertensive rats relative to monotherapies (Kolkhof et al., 2021). In particular, the diuretic effect of SGLT2 inhibitors could minimize the risk of MRA-related hyperkalemia, one of the remaining safety concerns for broad implementation of MRAs (Agarwal et al., 2021; Vukadinovic et al., 2017). The FIDELIO trial included only $5 \%$ of patients on SGLT2 inhibitors in the MRA arm (G. L. Bakris et al., 2020), which does not yet allow any conclusion to be drawn on this timely question. However, the prospect of more potent combination therapies is tempting in light of additive renoprotective effects, as well as related cardiovascular morbidity.

\section{Summary}


The role of MR signaling as an acute stress-response mechanism that can remain activated and promote chronic organ injury renders the MR a therapeutic target for many chronic disorders. Experimental and clinical MR research has come a long way and has consistently demonstrated the protective effects of MRAs on failing kidneys and the associated cardiovascular disease. There are still several safety concerns, even with new generation MRAs, e.g., hyperkalemia, which, however, is susceptible to co-administration of diuretics. Given the potent renoprotective effects of SGLT2 inhibitors, which induce osmotic diuresis, a triple combination of RAS/SGLT2 inhibitors plus a MRA may be particularly potent to maximize organ protection and minimize the risk of hyperkalemia, an evolving hypothesis to be tested in a clinical trial.

\section{Nomenclature of Targets and Ligands}

Key protein targets and ligands in this article are hyperlinked to corresponding entries in http://www.guidetopharmacology.org, and are permanently archived in the Concise Guide to PHARMACOLOGY 2021/22 (Alexander, Cidlowski, et al., 2021; Alexander, Kelly, Mathie, Peters, Veale, Armstrong, Faccenda, Harding, Pawson, Southan, Buneman, et al., 2021; Alexander, Kelly, Mathie, Peters, Veale, Armstrong, Faccenda, Harding, Pawson, Southan, Davies, et al., 2021).

\section{Funding}

This work was supported by the ANR NGAL-HT (ANR-19-CE14-0013), the Fondation de Recherche sur l'Hypertension Artérielle (REIN/NgalPA - 2017/2018), Fondation de France (CARDIO 00086498), and the Deutsche Forschungsgemeinschaft (AN372/30-1).

\section{Disclosures}

JB-C has nothing to disclose.

FJ received research grants from AstraZeneca and Bayer SAS and honoraria from Bayer SAS, and KBP Biosciences. 
HJA received honoraria from AstraZeneca, Boehringer, Bayer, Novartis, Janssen, and GSK. 


\section{Figure Legends}

Figure 1. Overview of the causes of CKD and the therapeutic options along the CKD progression timeline. Despite having different etiologies, glomerular and tubulointerstitial CKD both share nephron loss and fibrosis, leading to atrophy and renal dysfunction. When the origin of CKD is known, specific therapy against the original disease can be given. RAS and SGLT2 inhibitors represent the standard of care to slow CKD progression. The blockade of inflammation and fibrosis (e.g., with MRAs) could have an additional nephroprotective effect. As cardiovascular $(\mathrm{CV})$ risk increases as renal dysfunction worsens, the control of $\mathrm{CV}$ risk is essential in CKD patients.

Figure 2. Experimental and clinical evidence for a benefit of MRAs in renal diseases. MRAs show direct beneficial effects on renal function in several experimental models of kidney disease and clinical trials have yielded positive results in renal outcomes in diabetic and nondiabetic CKD. An additional reduction in cardiovascular risk has also been reported in several experimental and clinical studies. 


\section{REFERENCES}

Agarwal, R., Kolkhof, P., Bakris, G., Bauersachs, J., Haller, H., Wada, T., \& Zannad, F. (2021). Steroidal and non-steroidal mineralocorticoid receptor antagonists in cardiorenal medicine. Eur Heart J, 42(2), 152-161. doi:10.1093/eurheartj/ehaa736

Aldigier, J. C., Kanjanbuch, T., Ma, L. J., Brown, N. J., \& Fogo, A. B. (2005). Regression of existing glomerulosclerosis by inhibition of aldosterone. J Am Soc Nephrol, 16(11), 3306-3314. doi:10.1681/ASN.2004090804

Alexander, S. P., Cidlowski, J. A., Kelly, E., Mathie, A., Peters, J. A., Veale, E. L., ... Young, M. J. (2021). THE CONCISE GUIDE TO PHARMACOLOGY 2021/22: Nuclear hormone receptors. $\mathrm{Br} J$ Pharmacol, 178 Suppl 1, S246-S263. doi:10.1111/bph.15540

Alexander, S. P., Kelly, E., Mathie, A., Peters, J. A., Veale, E. L., Armstrong, J. F., ... Zolghadri, Y. (2021). THE CONCISE GUIDE TO PHARMACOLOGY 2021/22: Introduction and Other Protein Targets. Br J Pharmacol, 178 Suppl 1, S1-S26. doi:10.1111/bph.15537

Alexander, S. P., Kelly, E., Mathie, A., Peters, J. A., Veale, E. L., Armstrong, J. F., ... Verri, T. (2021). THE CONCISE GUIDE TO PHARMACOLOGY 2021/22: Transporters. Br J Pharmacol, 178 Suppl 1, S412-S513. doi:10.1111/bph.15543

Alexandrou, M. E., Papagianni, A., Tsapas, A., Loutradis, C., Boutou, A., Piperidou, A., ... Sarafidis, P. (2019). Effects of mineralocorticoid receptor antagonists in proteinuric kidney disease: a systematic review and meta-analysis of randomized controlled trials. J Hypertens, 37(12), 2307-2324. doi:10.1097/HJH.0000000000002187

Amador, C. A., Bertocchio, J. P., Andre-Gregoire, G., Placier, S., Duong Van Huyen, J. P., El Moghrabi, S., ... Jaisser, F. (2016). Deletion of mineralocorticoid receptors in smooth muscle cells blunts renal vascular resistance following acute cyclosporine administration. Kidney Int, 89(2), 354-362. doi:10.1038/ki.2015.312

Anders, H. J. (2012). Four danger response programs determine glomerular and tubulointerstitial kidney pathology: clotting, inflammation, epithelial and mesenchymal healing. Organogenesis, 8(2), 29-40. doi:10.4161/org.20342

Anders, H. J., Davis, J. M., \& Thurau, K. (2016). Nephron Protection in Diabetic Kidney Disease. N Engl J Med, 375(21), 2096-2098. doi:10.1056/NEJMcibr1608564

Anders, H. J., Huber, T. B., Isermann, B., \& Schiffer, M. (2018). CKD in diabetes: diabetic kidney disease versus nondiabetic kidney disease. Nat Rev Nephrol, 14(6), 361-377. doi:10.1038/s41581-018-0001-y

Arai, K., Morikawa, Y., Ubukata, N., Tsuruoka, H., \& Homma, T. (2016). CS-3150, a Novel Nonsteroidal Mineralocorticoid Receptor Antagonist, Shows Preventive and Therapeutic Effects On Renal Injury in Deoxycorticosterone Acetate/Salt-Induced Hypertensive Rats. J Pharmacol Exp Ther, 358(3), 548-557. doi:10.1124/jpet.116.234765

Arima, S., Kohagura, K., Xu, H. L., Sugawara, A., Abe, T., Satoh, F., ... Ito, S. (2003). Nongenomic vascular action of aldosterone in the glomerular microcirculation. $J \mathrm{Am}$ Soc Nephrol, 14(9), 2255-2263. doi:10.1097/01.asn.0000083982.74108.54

Asai, M., Monkawa, T., Marumo, T., Fukuda, S., Tsuji, M., Yoshino, J., ... Saruta, T. (2004). Spironolactone in combination with cilazapril ameliorates proteinuria and renal 
interstitial fibrosis in rats with anti-Thy-1 irreversible nephritis. Hypertens Res, 27(12), 971-978. Retrieved from https://www.ncbi.nlm.nih.gov/pubmed/15894838

Bakris, G., Pergola, P. E., Delgado, B., Genov, D., Doliashvili, T., Vo, N., ... Group, B.-C. S. (2021). Effect of KBP-5074 on Blood Pressure in Advanced Chronic Kidney Disease: Results of the BLOCK-CKD Study. Hypertension, 78(1), 74-81. doi:10.1161/HYPERTENSIONAHA.121.17073

Bakris, G., Yang, Y. F., \& Pitt, B. (2020). Mineralocorticoid Receptor Antagonists for Hypertension Management in Advanced Chronic Kidney Disease: BLOCK-CKD Trial. Hypertension, doi:10.1161/HYPERTENSIONAHA.120.15199

$76(1)$

144-149.

Bakris, G. L., Agarwal, R., Anker, S. D., Pitt, B., Ruilope, L. M., Rossing, P., ... Investigators, F.-D. (2020). Effect of Finerenone on Chronic Kidney Disease Outcomes in Type 2 Diabetes. $N$ Engl $J$ Med, 383(23), 2219-2229. doi:10.1056/NEJMoa2025845

Bakris, G. L., Agarwal, R., Chan, J. C., Cooper, M. E., Gansevoort, R. T., Haller, H., ... Mineralocorticoid Receptor Antagonist Tolerability Study-Diabetic Nephropathy Study, G. (2015). Effect of Finerenone on Albuminuria in Patients With Diabetic Nephropathy: A Randomized Clinical Trial. JAMA, 314(9), 884-894. doi:10.1001/jama.2015.10081

Bamberg, K., Johansson, U., Edman, K., William-Olsson, L., Myhre, S., Gunnarsson, A., ... Hartleib-Geschwindner, J. (2018). Preclinical pharmacology of AZD9977: A novel mineralocorticoid receptor modulator separating organ protection from effects on electrolyte excretion. PLoS One, 13(2), e0193380. doi:10.1371/journal.pone.0193380

Barba-Navarro, R., Tapia-Silva, M., Garza-Garcia, C., Lopez-Giacoman, S., Melgoza-Toral, I., Vazquez-Rangel, A., ... Madero, M. (2017). The Effect of Spironolactone on Acute Kidney Injury After Cardiac Surgery: A Randomized, Placebo-Controlled Trial. Am J Kidney Dis, 69(2), 192-199. doi:10.1053/j.ajkd.2016.06.013

Barrera-Chimal, J., Andre-Gregoire, G., Nguyen Dinh Cat, A., Lechner, S. M., Cau, J., Prince, S., ... Jaisser, F. (2017). Benefit of Mineralocorticoid Receptor Antagonism in AKI: Role of Vascular Smooth Muscle Rac1. J Am Soc Nephrol, 28(4), 1216-1226. doi:10.1681/ASN.2016040477

Barrera-Chimal, J., Girerd, S., \& Jaisser, F. (2019). Mineralocorticoid receptor antagonists and kidney diseases: pathophysiological basis. Kidney Int, 96(2), 302-319. doi:10.1016/j.kint.2019.02.030

Barrera-Chimal, J., Perez-Villalva, R., Ortega, J. A., Sanchez, A., Rodriguez-Romo, R., Durand, M., ... Bobadilla, N. A. (2015). Mild ischemic injury leads to long-term alterations in the kidney: amelioration by spironolactone administration. Int J Biol Sci, 11(8), 892-900. doi:10.7150/ijbs.11729

Barrera-Chimal, J., Perez-Villalva, R., Rodriguez-Romo, R., Reyna, J., Uribe, N., Gamba, G., \& Bobadilla, N. A. (2013). Spironolactone prevents chronic kidney disease caused by ischemic acute kidney injury. Kidney Int, 83(1), 93-103. doi:10.1038/ki.2012.352

Barrera-Chimal, J., Prince, S., Fadel, F., El Moghrabi, S., Warnock, D. G., Kolkhof, P., \& Jaisser, F. (2016). Sulfenic Acid Modification of Endothelin B Receptor is Responsible for the Benefit of a Nonsteroidal Mineralocorticoid Receptor Antagonist in Renal Ischemia. J Am Soc Nephrol, 27(2), 398-404. doi:10.1681/ASN.2014121216 
Barrera-Chimal, J., Rocha, L., Amador-Martinez, I., Perez-Villalva, R., Gonzalez, R., Cortes-Gonzalez, C., ... Bobadilla, N. A. (2018). Delayed spironolactone administration prevents the transition from acute kidney injury to chronic kidney disease through improving renal inflammation. Nephrol Dial Transplantdoi:10.1093/ndt/gfy246

Bhuiyan, A. S., Rafiq, K., Kobara, H., Masaki, T., Nakano, D., \& Nishiyama, A. (2019). Effect of a novel nonsteroidal selective mineralocorticoid receptor antagonist, esaxerenone (CS-3150), on blood pressure and renal injury in high salt-treated type 2 diabetic mice. Hypertens Res, 42(6), 892-902. doi:10.1038/s41440-019-0211-0

Bianchi, S., Bigazzi, R., \& Campese, V. M. (2005). Antagonists of aldosterone and proteinuria in patients with CKD: an uncontrolled pilot study. Am J Kidney Dis, 46(1), 45-51. doi:10.1053/j.ajkd.2005.03.007

Blasi, E. R., Rocha, R., Rudolph, A. E., Blomme, E. A., Polly, M. L., \& McMahon, E. G. (2003). Aldosterone/salt induces renal inflammation and fibrosis in hypertensive rats. Kidney Int, 63(5), 1791-1800. doi:10.1046/j.1523-1755.2003.00929.x

Bolignano, D., Palmer, S. C., Navaneethan, S. D., \& Strippoli, G. F. (2014). Aldosterone antagonists for preventing the progression of chronic kidney disease. Cochrane Database Syst Rev(4), CD007004. doi:10.1002/14651858.CD007004.pub3

Brandt-Jacobsen, N. H., Johansen, M. L., Rasmussen, J., Forman, J. L., Holm, M. R., Faber, J., ... Kistorp, C. (2020). Effect of high-dose mineralocorticoid receptor antagonist eplerenone on urinary albumin excretion in patients with type 2 diabetes and high cardiovascular risk: Data from the MIRAD trial. Diabetes Metabdoi:10.1016/j.diabet.2020.08.005

Brown, N. J., Nakamura, S., Ma, L., Nakamura, I., Donnert, E., Freeman, M., ... Fogo, A. B. (2000). Aldosterone modulates plasminogen activator inhibitor-1 and glomerulosclerosis in vivo. Kidney Int, 58(3), 1219-1227. doi:10.1046/j.15231755.2000.00277.x

Capelli, I., Gasperoni, L., Ruggeri, M., Donati, G., Baraldi, O., Sorrenti, G., ... La Manna, G. (2020). New mineralocorticoid receptor antagonists: update on their use in chronic kidney disease and heart failure. J Nephrol, 33(1), 37-48. doi:10.1007/s40620-01900600-7

Chapter 1: Definition and classification of CKD. (2013). Kidney Int Suppl (2011), 3(1), 1962. doi:10.1038/kisup.2012.64

Chen, H., Sun, F., Zhong, X., Shao, Y., Yoshimura, A., \& Liu, Y. (2013). Eplerenonemediated aldosterone blockade prevents renal fibrosis by reducing renal inflammation, interstitial cell proliferation and oxidative stress. Kidney Blood Press Res, 37(6), 557-566. doi:10.1159/000355736

Chevalier, R. L., \& Forbes, M. S. (2008). Generation and evolution of atubular glomeruli in the progression of renal disorders. J Am Soc Nephrol, 19(2), 197-206. doi:10.1681/ASN.2007080862

Chung, E. Y., Ruospo, M., Natale, P., Bolignano, D., Navaneethan, S. D., Palmer, S. C., \& Strippoli, G. F. (2020). Aldosterone antagonists in addition to renin angiotensin system antagonists for preventing the progression of chronic kidney disease. Cochrane Database Syst Rev, 10, CD007004. doi:10.1002/14651858.CD007004.pub4 
Cp, C. (2017). Pharmacological Profile of KBP-5074, a Novel NonSteroidal Mineralocorticoid Receptor Antagonist for the Treatment of Cardiorenal Diseases. Journal of Drug Research and Development, 3(3)doi:10.16966/2470-1009.137

Currie, G., Taylor, A. H., Fujita, T., Ohtsu, H., Lindhardt, M., Rossing, P., ... Mark, P. B. (2016). Effect of mineralocorticoid receptor antagonists on proteinuria and progression of chronic kidney disease: a systematic review and meta-analysis. $B M C$ Nephrol, 17(1), 127. doi:10.1186/s12882-016-0337-0

Dong, D., Fan, T. T., Ji, Y. S., Yu, J. Y., Wu, S., \& Zhang, L. (2019). Spironolactone alleviates diabetic nephropathy through promoting autophagy in podocytes. Int Urol Nephrol, 51(4), 755-764. doi:10.1007/s11255-019-02074-9

Feria, I., Pichardo, I., Juarez, P., Ramirez, V., Gonzalez, M. A., Uribe, N., ... Bobadilla, N. A. (2003). Therapeutic benefit of spironolactone in experimental chronic cyclosporine A nephrotoxicity. Kidney Int, 63(1), 43-52. doi:10.1046/j.15231755.2003.00707.x

Fujihara, C. K., Kowala, M. C., Breyer, M. D., Sena, C. R., Rodrigues, M. V., Arias, S. C. A., ... Zatz, R. (2017). A Novel Aldosterone Antagonist Limits Renal Injury in 5/6 Nephrectomy. Sci Rep, 7(1), 7899. doi:10.1038/s41598-017-08383-2

Fujisawa, G., Okada, K., Muto, S., Fujita, N., Itabashi, N., Kusano, E., \& Ishibashi, S. (2004). Spironolactone prevents early renal injury in streptozotocin-induced diabetic rats. Kidney Int, 66(4), 1493-1502. doi:10.1111/j.1523-1755.2004.00913.x

Girerd, S., Frimat, L., Ducloux, D., Le Meur, Y., Mariat, C., Moulin, B., ... Jaisser, F. (2018). EPURE Transplant (Eplerenone in Patients Undergoing Renal Transplant) study: study protocol for a randomized controlled trial. Trials, 19(1), 595. doi:10.1186/s13063-018-2956-1

Greene, E. L., Kren, S., \& Hostetter, T. H. (1996). Role of aldosterone in the remnant kidney model in the rat. $J$ Clin Invest, 98(4), 1063-1068. doi:10.1172/JCI118867

Grune, J., Beyhoff, N., Smeir, E., Chudek, R., Blumrich, A., Ban, Z., .. Kintscher, U. (2018). Selective Mineralocorticoid Receptor Cofactor Modulation as Molecular Basis for Finerenone's Antifibrotic Activity. Hypertension, 71(4), 599-608. doi:10.1161/HYPERTENSIONAHA.117.10360

Gullulu, M., Akdag, I., Kahvecioglu, S., Filiz, G., \& Savci, V. (2006). Aldosterone blockage in proliferative glomerulonephritis prevents not only fibrosis, but proliferation as well. Ren Fail, 28(6), 509-514. doi:10.1080/08860220600779033

Guo, C., Martinez-Vasquez, D., Mendez, G. P., Toniolo, M. F., Yao, T. M., Oestreicher, E. M., ... Adler, G. K. (2006). Mineralocorticoid receptor antagonist reduces renal injury in rodent models of types 1 and 2 diabetes mellitus. Endocrinology, 147(11), 5363-5373. doi:10.1210/en.2006-0944

Han, K. H., Kang, Y. S., Han, S. Y., Jee, Y. H., Lee, M. H., Han, J. Y., ... Cha, D. R. (2006). Spironolactone ameliorates renal injury and connective tissue growth factor expression in type II diabetic rats. Kidney Int, 70(1), 111-120. doi:10.1038/sj.ki.5000438

Han, S. Y., Kim, C. H., Kim, H. S., Jee, Y. H., Song, H. K., Lee, M. H., ... Cha, D. R. (2006). Spironolactone prevents diabetic nephropathy through an anti-inflammatory mechanism in type 2 diabetic rats. J Am Soc Nephrol, 17(5), 1362-1372. doi:10.1681/ASN.2005111196 
Heerspink, H. J. L., Stefansson, B. V., Correa-Rotter, R., Chertow, G. M., Greene, T., Hou, F. F., ... Investigators. (2020). Dapagliflozin in Patients with Chronic Kidney Disease. N Engl J Med, 383(15), 1436-1446. doi:10.1056/NEJMoa2024816

Helal, I., Fick-Brosnahan, G. M., Reed-Gitomer, B., \& Schrier, R. W. (2012). Glomerular hyperfiltration: definitions, mechanisms and clinical implications. Nat Rev Nephrol, 8(5), 293-300. doi:10.1038/nrneph.2012.19

Hostetter, T. H., Olson, J. L., Rennke, H. G., Venkatachalam, M. A., \& Brenner, B. M. (1981). Hyperfiltration in remnant nephrons: a potentially adverse response to renal ablation. Am J Physiol, 241(1), F85-93. doi:10.1152/ajprenal.1981.241.1.F85

Hou, J., Xiong, W., Cao, L., Wen, X., \& Li, A. (2015). Spironolactone Add-on for Preventing or Slowing the Progression of Diabetic Nephropathy: A Meta-analysis. Clin Ther, 37(9), 2086-2103 e2010. doi:10.1016/j.clinthera.2015.05.508

Huang, L. L., Nikolic-Paterson, D. J., Han, Y., Ozols, E., Ma, F. Y., Young, M. J., \& Tesch, G. H. (2014). Myeloid mineralocorticoid receptor activation contributes to progressive kidney disease. J Am Soc Nephrol, 25(10), 2231-2240. doi:10.1681/ASN.2012111094

Ito, S., Shikata, K., Nangaku, M., Okuda, Y., \& Sawanobori, T. (2019). Efficacy and Safety of Esaxerenone (CS-3150) for the Treatment of Type 2 Diabetes with Microalbuminuria: A Randomized, Double-Blind, Placebo-Controlled, Phase II Trial. Clin J Am Soc Nephrol, 14(8), 1161-1172. doi:10.2215/CJN.14751218

Jaisser, F., Tan, X., Chi, S., Liu, J., Wang, P., Bush, M., ... Zhang, J. (2021). The NonSteroidal Mineralocorticoid Receptor Antagonist KBP-5074 Limits Albuminuria and has Improved Therapeutic Index Compared With Eplerenone in a Rat Model With Mineralocorticoid-Induced Renal Injury. Front Pharmacol, 12, 604928. doi:10.3389/fphar.2021.604928

Jeewandara, T. M., Ameer, O. Z., Boyd, R., Wyse, B. F., Underwood, C. F., \& Phillips, J. K. (2015). Protective cardiorenal effects of spironolactone in a rodent model of polycystic kidney disease. Clin Exp Pharmacol Physiol, 42(4), 353-360. doi:10.1111/1440-1681.12372

Kalluri, R., \& Neilson, E. G. (2003). Epithelial-mesenchymal transition and its implications for fibrosis. J Clin Invest, 112(12), 1776-1784. doi:10.1172/JCI20530

Kolkhof, P., Delbeck, M., Kretschmer, A., Steinke, W., Hartmann, E., Barfacker, L., ... Schafer, S. (2014). Finerenone, a novel selective nonsteroidal mineralocorticoid receptor antagonist protects from rat cardiorenal injury. J Cardiovasc Pharmacol, 64(1), 69-78. doi:10.1097/FJC.0000000000000091

Kolkhof, P., Hartmann, E., Freyberger, A., Pavkovic, M., Mathar, I., Sandner, P., ... Eitner, F. (2021). Effects of Finerenone Combined with Empagliflozin in a Model of Hypertension-Induced End-Organ Damage. Am J Nephrol, 1-11. doi:10.1159/000516213

Kolkhof, P., Nowack, C., \& Eitner, F. (2015). Nonsteroidal antagonists of the mineralocorticoid receptor. Curr Opin Nephrol Hypertens, 24(5), 417-424. doi:10.1097/MNH.0000000000000147

Kopp, J. B., Anders, H. J., Susztak, K., Podesta, M. A., Remuzzi, G., Hildebrandt, F., \& Romagnani, P. (2020). Podocytopathies. Nat Rev Dis Primers, 6(1), 68. doi:10.1038/s41572-020-0196-7

Lachaux, M., Barrera-Chimal, J., Nicol, L., Remy-Jouet, I., Renet, S., Dumesnil, A., ... Mulder, P. (2018). Short- and long-term administration of the non-steroidal 
mineralocorticoid receptor antagonist finerenone opposes metabolic syndromerelated cardio-renal dysfunction. Diabetes Obes Metab, 20(10), 2399-2407. doi:10.1111/dom. 13393

Lahmer, T., Hermans, R., Schmaderer, C., Chang, J., Stock, K., Lutz, J., ... Baumann, M. (2012). Mineralocorticoid receptor antagonism and aldosterone synthesis inhibition do not improve glomerulosclerosis and renal interstitial fibrosis in a model of chronic kidney allograft injury. Kidney Blood Press Res, 35(6), 561-567. doi:10.1159/000339649

Lattenist, L., Lechner, S. M., Messaoudi, S., Le Mercier, A., El Moghrabi, S., Prince, S., ... Barrera-Chimal, J. (2017). Nonsteroidal Mineralocorticoid Receptor Antagonist Finerenone Protects Against Acute Kidney Injury-Mediated Chronic Kidney Disease: Role of Oxidative Stress. Hypertension, 69(5), 870-878. doi:10.1161/HYPERTENSIONAHA.116.08526

Leader, C. J., Kelly, D. J., Sammut, I. A., Wilkins, G. T., \& Walker, R. J. (2020). Spironolactone mitigates, but does not reverse, the progression of renal fibrosis in a transgenic hypertensive rat. Physiol Rep, 8(10), e14448. doi:10.14814/phy2.14448

Lei, Y., \& Anders, H. J. (2017). Evolutionary trade-offs in kidney injury and repair. Histol Histopathol, 32(11), 1099-1113. doi:10.14670/HH-11-900

Li, L., Guan, Y., Kobori, H., Morishita, A., Kobara, H., Masaki, T., ... Nishiyama, A. (2019). Effects of the novel nonsteroidal mineralocorticoid receptor blocker, esaxerenone (CS-3150), on blood pressure and urinary angiotensinogen in low-renin Dahl saltsensitive hypertensive rats. Hypertens Res, 42(6), 769-778. doi:10.1038/s41440-018$0187-1$

Lian, M., Hewitson, T. D., Wigg, B., Samuel, C. S., Chow, F., \& Becker, G. J. (2012). Longterm mineralocorticoid receptor blockade ameliorates progression of experimental diabetic renal disease. Nephrol Dial Transplant, 27(3), 906-912. doi:10.1093/ndt/gfr495

Lindhardt, J. L., Nielsen, P. M., Hansen, E. S. S., Qi, H., Tougaard, R. S., Mariager, C. O., ... Laustsen, C. (2020). The hemodynamic and metabolic effects of spironolactone treatment in acute kidney injury assessed by hyperpolarized MRI. NMR Biomed, 33(10), e4371. doi:10.1002/nbm.4371

Ma, F. Y., Han, Y., Nikolic-Paterson, D. J., Kolkhof, P., \& Tesch, G. H. (2015). Suppression of Rapidly Progressive Mouse Glomerulonephritis with the Non-Steroidal Mineralocorticoid Receptor Antagonist BR-4628. PLoS One, 10(12), e0145666. doi:10.1371/journal.pone.0145666

McAuley, F. T., Whiting, P. H., Thomson, A. W., \& Simpson, J. G. (1987). The influence of enalapril or spironolactone on experimental cyclosporin nephrotoxicity. Biochem Pharmacol, $\quad 36(5), \quad$ 699-703. 0 Retrieved from https://www.ncbi.nlm.nih.gov/pubmed/3030332

Medeiros, M., Velasquez-Jones, L., Hernandez, A. M., Ramon-Garcia, G., Valverde, S., Fuentes, Y., ... Bobadilla, N. A. (2017). Randomized Controlled Trial of Mineralocorticoid Receptor Blockade in Children with Chronic Kidney Allograft Nephropathy. Clin J Am Soc Nephrol, 12(8), 1291-1300. doi:10.2215/CJN.05300516

Mejia-Vilet, J. M., Ramirez, V., Cruz, C., Uribe, N., Gamba, G., \& Bobadilla, N. A. (2007). Renal ischemia-reperfusion injury is prevented by the mineralocorticoid receptor blocker spironolactone. Am J Physiol Renal Physiol, 293(1), F78-86. doi:10.1152/ajprenal.00077.2007 
Melis, N., Thuillier, R., Steichen, C., Giraud, S., Sauvageon, Y., Kaminski, J., ... Hauet, T. (2019). Emerging therapeutic strategies for transplantation-induced acute kidney injury: protecting the organelles and the vascular bed. Expert Opin Ther Targets, 23(6), 495-509. doi:10.1080/14728222.2019.1609451

Mihailidou, A. S., Tzakos, A. G., \& Ashton, A. W. (2019). Non-Genomic Effects of Aldosterone. Vitam Horm, 109, 133-149. doi:10.1016/bs.vh.2018.12.001

Minakuchi, H., Wakino, S., Urai, H., Kurokochi, A., Hasegawa, K., Kanda, T., ... Itoh, H. (2020). The effect of aldosterone and aldosterone blockade on the progression of chronic kidney disease: a randomized placebo-controlled clinical trial. Sci Rep, 10(1), 16626. doi:10.1038/s41598-020-73638-4

Morales-Buenrostro, L. E., Ortega-Trejo, J. A., Perez-Villalva, R., Marino, L. A., GonzalezBobadilla, Y., Juarez, H., ... Bobadilla, N. A. (2019). Spironolactone reduces oxidative stress in living donor kidney transplantation: a randomized controlled trial. Am J Physiol Renal Physiol, 317(3), F519-F528. doi:10.1152/ajprenal.00606.2018

Mortensen, L. A., Bistrup, C., Stubbe, J., Carlstrom, M., Checa, A., Wheelock, C. E., ... Jensen, B. L. (2019). Effect of spironolactone for $1 \mathrm{yr}$ on endothelial function and vascular inflammation biomarkers in renal transplant recipients. Am J Physiol Renal Physiol, 317(3), F529-F539. doi:10.1152/ajprenal.00025.2019

Mortensen, L. A., Thiesson, H. C., Tougaard, B., Egfjord, M., Fischer, A. S. L., \& Bistrup, C. (2018). The effect of spironolactone on calcineurin inhibitor induced nephrotoxicity: a multicenter randomized, double-blind, clinical trial (the SPIREN trial). BMC Nephrol, 19(1), 105. doi:10.1186/s12882-018-0885-6

Mujtaba, A., Taher, M. A., Hazza, M. A., Al-Rubaye, H. M., Kata, A. H., AbdulWahab, H., ... AlRubay, H. K. (2018). The Effect of Spironolactone on the Incidence of ContrastInduced Nephropathy in Patients Undergoing Cardiac Catheterization: Study Design and Rationale. Cardiol Ther, 7(1), 101-106. doi:10.1007/s40119-018-0112-3

Nagase, M., Matsui, H., Shibata, S., Gotoda, T., \& Fujita, T. (2007). Salt-induced nephropathy in obese spontaneously hypertensive rats via paradoxical activation of the mineralocorticoid receptor: role of oxidative stress. Hypertension, 50(5), 877-883. doi:10.1161/HYPERTENSIONAHA.107.091058

Nagase, M., Shibata, S., Yoshida, S., Nagase, T., Gotoda, T., \& Fujita, T. (2006). Podocyte injury underlies the glomerulopathy of Dahl salt-hypertensive rats and is reversed by aldosterone blocker. Hypertension, 47(6), 1084-1093. doi:10.1161/01.HYP.0000222003.28517.99

Nariai, T., Fujita, K., Mori, M., Katayama, S., Hori, S., \& Matsui, K. (2012). Antihypertensive and cardiorenal protective effects of SM-368229, a novel mineralocorticoid receptor antagonist, in aldosterone/salt-treated rats. Pharmacology, 89(1-2), 44-52. doi:10.1159/000335559

Nielsen, F. T., Jensen, B. L., Hansen, P. B., Marcussen, N., \& Bie, P. (2013). The mineralocorticoid receptor antagonist eplerenone reduces renal interstitial fibrosis after long-term cyclosporine treatment in rat: antagonizing cyclosporine nephrotoxicity. BMC Nephrol, 14, 42. doi:10.1186/1471-2369-14-42

Nielsen, F. T., Jensen, B. L., Marcussen, N., Skott, O., \& Bie, P. (2008). Inhibition of mineralocorticoid receptors with eplerenone alleviates short-term cyclosporin A nephrotoxicity in conscious rats. Nephrol Dial Transplant, 23(9), 2777-2783. doi:10.1093/ndt/gfn204 
Ojeda-Cervantes, M., Barrera-Chimal, J., Alberu, J., Perez-Villalva, R., Morales-Buenrostro, L. E., \& Bobadilla, N. A. (2013). Mineralocorticoid receptor blockade reduced oxidative stress in renal transplant recipients: a double-blind, randomized pilot study. Am J Nephrol, 37(5), 481-490. doi:10.1159/000350539

Perez-Rojas, J., Blanco, J. A., Cruz, C., Trujillo, J., Vaidya, V. S., Uribe, N., ... Bobadilla, N. A. (2007). Mineralocorticoid receptor blockade confers renoprotection in preexisting chronic cyclosporine nephrotoxicity. Am J Physiol Renal Physiol, 292(1), F131-139. doi:10.1152/ajprenal.00147.2006

Perez-Rojas, J. M., Derive, S., Blanco, J. A., Cruz, C., Martinez de la Maza, L., Gamba, G., \& Bobadilla, N. A. (2005). Renocortical mRNA expression of vasoactive factors during spironolactone protective effect in chronic cyclosporine nephrotoxicity. Am J Physiol Renal Physiol, 289(5), F1020-1030. doi:10.1152/ajprenal.00166.2005

Perkovic, V., Jardine, M. J., Neal, B., Bompoint, S., Heerspink, H. J. L., Charytan, D. M., ... Investigators, C. T. (2019). Canagliflozin and Renal Outcomes in Type 2 Diabetes and Nephropathy. N Engl J Med, 380(24), 2295-2306. doi:10.1056/NEJMoa1811744

Pessoa, B. S., Peixoto, E. B., Papadimitriou, A., Lopes de Faria, J. M., \& Lopes de Faria, J. B. (2012). Spironolactone improves nephropathy by enhancing glucose-6-phosphate dehydrogenase activity and reducing oxidative stress in diabetic hypertensive rat. $J$ Renin Angiotensin Aldosterone Syst, 13(1), 56-66. doi:10.1177/1470320311422581

Pretorius, M., Murray, K. T., Yu, C., Byrne, J. G., Billings, F. T. t., Petracek, M. R., ... Brown, N. J. (2012). Angiotensin-converting enzyme inhibition or mineralocorticoid receptor blockade do not affect prevalence of atrial fibrillation in patients undergoing cardiac surgery. Crit Care Med, 40(10), 2805-2812. doi:10.1097/CCM.0b013e31825b8be2

Qin, D., Morita, H., Inui, K., Tayama, H., Inoue, Y., \& Yoshimura, A. (2013). Aldosterone mediates glomerular inflammation in experimental mesangial proliferative glomerulonephritis. J Nephrol, 26(1), 199-206. doi:10.5301/jn.5000125

Rocha, R., Chander, P. N., Zuckerman, A., \& Stier, C. T., Jr. (1999). Role of aldosterone in renal vascular injury in stroke-prone hypertensive rats. Hypertension, 33(1 Pt 2), 232237. Retrieved from https://www.ncbi.nlm.nih.gov/pubmed/9931110

Romagnani, P., Remuzzi, G., Glassock, R., Levin, A., Jager, K. J., Tonelli, M., ... Anders, H. J. (2017). Chronic kidney disease. Nat Rev Dis Primers, 3, 17088. doi:10.1038/nrdp.2017.88

Ruggenenti, P., Perna, A., Gherardi, G., Garini, G., Zoccali, C., Salvadori, M., ... Remuzzi, G. (1999). Renoprotective properties of ACE-inhibition in non-diabetic nephropathies with non-nephrotic proteinuria. Lancet, 354(9176), 359-364. doi:10.1016/S0140-6736(98)10363-X

Sanchez-Pozos, K., Barrera-Chimal, J., Garzon-Muvdi, J., Perez-Villalva, R., RodriguezRomo, R., Cruz, C., ... Bobadilla, N. A. (2012). Recovery from ischemic acute kidney injury by spironolactone administration. Nephrol Dial Transplant, 27(8), 3160-3169. doi:10.1093/ndt/gfs014

Scheen, A. J. (2020). Reduction in HbA1c with SGLT2 inhibitors vs. DPP-4 inhibitors as add-ons to metformin monotherapy according to baseline HbAlc: A systematic review of randomized controlled trials. Diabetes Metab, 46(3), 186-196. doi:10.1016/j.diabet.2020.01.002 
Sharma, S., \& Smyth, B. (2021). From Proteinuria to Fibrosis: An Update on Pathophysiology and Treatment Options. Kidney Blood Press Res, 1-10. doi:10.1159/000516911

Thomas, M. C., \& Cherney, D. Z. I. (2018). The actions of SGLT2 inhibitors on metabolism, renal function and blood pressure. Diabetologia, 61(10), 2098-2107. doi:10.1007/s00125-018-4669-0

Tokuyama, H., Wakino, S., Hara, Y., Washida, N., Fujimura, K., Hosoya, K., ... Itoh, H. (2012). Role of mineralocorticoid receptor/Rho/Rho-kinase pathway in obesityrelated renal injury. Int J Obes (Lond), 36(8), 1062-1071. doi:10.1038/ijo.2011.232

Toyonaga, J., Tsuruya, K., Ikeda, H., Noguchi, H., Yotsueda, H., Fujisaki, K., ... Iida, M. (2011). Spironolactone inhibits hyperglycemia-induced podocyte injury by attenuating ROS production. Nephrol Dial Transplant, 26(8), 2475-2484. doi:10.1093/ndt/gfq750

Trachtman, H., Weiser, A. C., Valderrama, E., Morgado, M., \& Palmer, L. S. (2004). Prevention of renal fibrosis by spironolactone in mice with complete unilateral ureteral obstruction. $J$ Urol, $172(4$ Pt 2), 1590-1594. Retrieved from https://www.ncbi.nlm.nih.gov/pubmed/15371767.

Vaduganathan, M., Claggett, B. L., Jhund, P. S., Cunningham, J. W., Pedro Ferreira, J., Zannad, F., ... Solomon, S. D. (2020). Estimating lifetime benefits of comprehensive disease-modifying pharmacological therapies in patients with heart failure with reduced ejection fraction: a comparative analysis of three randomised controlled trials. Lancet, 396(10244), 121-128. doi:10.1016/S0140-6736(20)30748-0

Vallon, V. (2015). The mechanisms and therapeutic potential of SGLT2 inhibitors in diabetes mellitus. Annu Rev Med, 66, 255-270. doi:10.1146/annurev-med-051013-110046

van der Horst, I. C., Voors, A. A., \& van Veldhuisen, D. J. (2007). Treatment of heart failure with ACE inhibitors and beta-blockers: what is next? Aldosterone receptor antagonists? Clin Res Cardiol, 96(4), 193-195. doi:10.1007/s00392-007-0487-y

Voelker, J., Berg, P. H., Sheetz, M., Duffin, K., Shen, T., Moser, B., ... Lewis, J. B. (2017). Anti-TGF-betal Antibody Therapy in Patients with Diabetic Nephropathy. J Am Soc Nephrol, 28(3), 953-962. doi:10.1681/ASN.2015111230

Vukadinovic, D., Lavall, D., Vukadinovic, A. N., Pitt, B., Wagenpfeil, S., \& Bohm, M. (2017). True rate of mineralocorticoid receptor antagonists-related hyperkalemia in placebo-controlled trials: A meta-analysis. Am Heart $J$, 188, 99-108. doi:10.1016/j.ahj.2017.03.011

Waanders, F., Rienstra, H., Boer, M. W., Zandvoort, A., Rozing, J., Navis, G., ... Hillebrands, J. L. (2009). Spironolactone ameliorates transplant vasculopathy in renal chronic transplant dysfunction in rats. Am J Physiol Renal Physiol, 296(5), F10721079. doi:10.1152/ajprenal.90643.2008

Wada, T., Inagaki, M., Yoshinari, T., Terata, R., Totsuka, N., Gotou, M., \& Hashimoto, G. (2020). Apararenone in patients with diabetic nephropathy: results of a randomized, double-blind, placebo-controlled phase 2 dose-response study and open-label extension study. Clin Exp Nephroldoi:10.1007/s10157-020-01963-z

Wanner, C., Inzucchi, S. E., Lachin, J. M., Fitchett, D., von Eynatten, M., Mattheus, M., ... Investigators, E.-R. O. (2016). Empagliflozin and Progression of Kidney Disease in Type 2 Diabetes. $N$ Engl J Med, 375(4), 323-334. doi:10.1056/NEJMoa1515920

Xiong, Y., Chang, Y., Hao, J., Zhang, C., Yang, F., Wang, Z., ... Xu, Q. (2021). Eplerenone Attenuates Fibrosis in the Contralateral Kidney of UUO Rats by Preventing 
Macrophage-to-Myofibroblast Transition. Front Pharmacol, 12, 620433. doi:10.3389/fphar.2021.620433

Yang, C. T., Kor, C. T., \& Hsieh, Y. P. (2018). Long-Term Effects of Spironolactone on Kidney Function and Hyperkalemia-Associated Hospitalization in Patients with Chronic Kidney Disease. J Clin Med, 7(11)doi:10.3390/jcm7110459

Yoshida, S., Ishizawa, K., Ayuzawa, N., Ueda, K., Takeuchi, M., Kawarazaki, W., ... Nagase, M. (2014). Local mineralocorticoid receptor activation and the role of Rac1 in obesity-related diabetic kidney disease. Nephron Exp Nephrol, 126(1), 16-24. doi: $10.1159 / 000358758$

Yu, B. C., Lee, M. S., Moon, J. J., Choi, S. J., Kim, J. K., Hwang, S. D., \& Park, M. Y. (2018). Efficacy of low-dose spironolactone on top of angiotensin receptor blockade in patients with glomerulonephritis. Kidney Res Clin Pract, 37(3), 257-265. doi:10.23876/j.krcp.2018.37.3.257

Yuan, J., Jia, R., \& Bao, Y. (2007). Beneficial effects of spironolactone on glomerular injury in streptozotocin-induced diabetic rats. J Renin Angiotensin Aldosterone Syst, 8(3), 118-126. doi:10.3317/jraas.2007.014

Zannad, F., Ferreira, J. P., Pocock, S. J., Anker, S. D., Butler, J., Filippatos, G., ... Packer, M. (2020). SGLT2 inhibitors in patients with heart failure with reduced ejection fraction: a meta-analysis of the EMPEROR-Reduced and DAPA-HF trials. Lancet, 396(10254), 819-829. doi:10.1016/S0140-6736(20)31824-9

Zhou, X., Ono, H., Ono, Y., \& Frohlich, E. D. (2004). Aldosterone antagonism ameliorates proteinuria and nephrosclerosis independent of glomerular dynamics in LNAME/SHR model. Am J Nephrol, 24(2), 242-249. doi:10.1159/000077396

Zinman, B., Wanner, C., Lachin, J. M., Fitchett, D., Bluhmki, E., Hantel, S., ... Investigators, E.-R. O. (2015). Empagliflozin, Cardiovascular Outcomes, and Mortality in Type 2 Diabetes. $N$ Engl J Med, 373(22), 2117-2128. doi:10.1056/NEJMoa1504720

Zitt, E., Eller, K., Huber, J. M., Kirsch, A. H., Tagwerker, A., Mayer, G., \& Rosenkranz, A. R. (2011). The selective mineralocorticoid receptor antagonist eplerenone is protective in mild anti-GBM glomeru-lonephritis. Int J Clin Exp Pathol, 4(6), 606615. Retrieved from https://www.ncbi.nlm.nih.gov/pubmed/21904636 